\title{
Foliar Reflectance and Fluorescence Responses for Plants Under Nitrogen Stress Determined with Active and Passive Systems
}

\author{
Middleton, E.M. ${ }^{1 \#}$, J.E. McMurtrey ${ }^{2}$, P.K. Entcheva Campbell ${ }^{1}$, L.A. Corp ${ }^{1}$, \\ L.M. Butcher ${ }^{1}$, and E.W. Chappelle ${ }^{1}$
}

\footnotetext{
' Biospheric Sciences Branch, Laboratory for Terrestrial Physics, NASA/GSFC, Greenbelt, MD 20771

${ }^{2}$ Hydrology \& Remote Sensing Laboratory, Agricultural Research Service, USDA, Beltsville, MD 20705

\# Corresponding Author: email, Elizabeth.M.Middleton@nasa.gov Fax Number, +1 301-614-6695
}

\begin{abstract}
Vegetation productivity is driven by nitrogen (N) availability in soils. Both excessive and low soil $\mathrm{N}$ induce physiological changes in plant foliage. In 2001 , we examined the use of spectral fluorescence and reflectance measurements to discriminate among plants provided different $\mathrm{N}$ fertilizer application rates: $20 \%, 50 \%, 100 \%$ and $150 \%$ of optimal $\mathrm{N}$ levels. A suite of optical, fluorescence, and biophysical measurements were collected on leaves from field grown corn (Zea mays L.) and soybean plants (Glycine max L.) grown in pots (greenhouse + ambient sunlight daily). Three types of steady state laser-induced fluorescence measurements were made on adaxial and abaxial surfaces: 1) fluorescence images in four $10 \mathrm{~nm}$ bands (blue, green, red, far-red) resulting from broad irradiance excitation; 2) emission spectra (5 nm resolution) produced by excitation at single wavelengths (280,380 or 360, and $532 \mathrm{~nm})$; and 3) excitation spectra ( $2 \mathrm{~nm}$ resolution), with emission wavelengths fixed at wavelengths centered on selected solar Fraunhofer lines $(532,607,677$ and $745 \mathrm{~nm})$. Two complementary sets of high resolution ( $<2 \mathrm{~nm}$ ) optical spectra were acquired for both adaxial and abaxial leaf surfaces: 1$)$ optical properties (350-2500 nm) for reflectance, transmittance, and absorptance; and 2) reflectance spectra (500-1000 nm) acquired with and without a short pass filter at $665 \mathrm{~nm}$ to determine the fluorescence contribution to "apparent reflectance" in the 650-750 spectrum, especially at the 685 and $740 \mathrm{~nm}$ chlorophyll fluorescence (ChlF) peaks. The strongest relationships between foliar chemistry and optical properties were demonstrated for $\mathrm{C} / \mathrm{N}$ content and two optical parameters associated with the "red edge inflection point". Select optical properties and ChlF parameters were highly correlated for both species. A significant contribution of ChlF to "apparent reflectance" was observed, averaging 10-25\% at $685 \mathrm{~nm}$ and 2$6 \%$ at $740 \mathrm{~nm}$ over all $\mathrm{N}$ treatments. Discrimination of $\mathrm{N}$ treatment groups was possible with specific fluorescence band ratios (e.g., F740/F525 obtained with 380EX). From all measurements assessing fluorescence, higher $\mathrm{ChlF}$ and blue/green emissions were measured from the abaxial leaf surfaces; Abaxial surfaces also produced higher reflectances in the 400-800 $\mathrm{nm}$ spectrum. Fluorescence information collected in Fraunhofer regions located on the shoulders of ChlF features compared favorably with peak emissions. This supports the potential capability of a future space-born interferometer sensor to capture plant canopy fluorescence.
\end{abstract}

IGARSS'03, Toulouse, France

July $21-25,2003$

For proposed (N01) NEW TOPICS (Oral session on "Vegetation Fluorescence")

Attention: Marc-Philippe Stoll; mpstoll@sepia.u-strasbg.fr and

Michael Berger; Michael.Berger@esa.int 